\title{
Application of information entropy and TOPSIS coupling model in impervious design of hydraulic engineering
}

\author{
Shu Zhang ${ }^{1, *}$ \\ ${ }^{1}$ Management Science and engineering, School of Management, Tianjin University of Technology, China
}

\begin{abstract}
The establishment of a scientific and reasonable mathematical evaluation model plays a vital role in the optimization of impervious design scheme of water conservancy projects. The steps of constructing the coupling model of information entropy and TOPSIS are analyzed. The seepage prevention design scheme of an urban artificial lake is comprehensively evaluated by using this model, so as to obtain the optimal scheme.
\end{abstract}

\section{The introduction}

In this paper, a coupling model of information entropy and TOPSIS is established, and objective data mining and weight assignment are carried out for evaluation indexes in the model, so as to solve many problems, such as low accuracy of objective quantization of evaluation indexes weight and inability to objectively reflect the connection between data information and practical schemes.

\section{The coupling model of information entropy and TOPSIS was constructed}

\subsection{Establish a scheme optimization evaluation system}

This work includes dimensionless processing of evaluation sample data and standardized processing of program evaluation value. Assume $m$ schemes, $n$ evaluation indexes, and the decision matrix is $X=$ $\left(x_{i j}\right)_{m \times n}$. The original data are transformed according to the standardized method, as shown in Equation (1). Then, different dimensions are normalized to complete the transformation from the actual value to the evaluation value of the index.

$$
X_{i j}^{\prime}=\frac{X_{i j}-\bar{X}_{j}}{S_{j}}
$$

In the formula: $\bar{X}_{j}$ is the mean of the index $j . S_{j}$ is the standard deviation of the value of $j$. For very large indicators, such as engineering effect, construction technology, investment, etc., the actual value is converted into the index evaluation value according to Formula (2). For very small indicators, such as construction difficulty, environmental impact, etc., the actual value is converted into the index evaluation value according to equation (3).

$$
r_{i j}=\frac{x_{i j}}{x 0 j}=\frac{x_{i j}}{\max _{k} x_{k j}}
$$

In the formula: $\max _{k} x_{k j}=x_{k 1} \vee x_{k 2} \vee \cdots \vee x_{k n}$

$$
r_{i j}=\frac{x 0 j}{x_{i j}}=\frac{\max _{k} x_{k j}}{x_{i j}}
$$

In the formula: $\max _{k} x_{k j}=x_{k 1} \wedge x_{k 2} \wedge \cdots \wedge x_{k n}$

Finally, the ideal solution $r^{*}{ }_{j}$ of the normalized decision matrix is determined, as shown in Equation (4). Among them,$J^{+}=$(Very large index $), J^{-}=($Very small indicator).

$$
\begin{gathered}
r_{j}^{*}=\left\{\begin{array}{l}
\max _{1 \leq i \leq m} r_{i j} j \in J^{+} \\
\min _{1 \leq i \leq m} r_{i j} j \in J^{-}
\end{array}\right. \\
j=1,2, \quad \cdots, n
\end{gathered}
$$

\subsection{The determination of evaluation index weight}

Information entropy gives weight to the information amount of data (such as investment, construction process, time limit and other factors) and evaluation indexes in the scheme [1]. TOPSIS method is comprehensively considered to obtain the implicit index weight from the information of each index, and then the weight value is integrated to obtain the final weight of each evaluation index. The expression of information entropy to solve the weight $w_{i}$ of each evaluation index is shown in Equation (5). The TOPSIS method is used to calculate the weight $w_{j}$ of each index, as shown in Equation (6). The coupling model uses comprehensive weight to assign weight to each evaluation index, and its calculation formula is shown in Formula (7).

$$
\begin{gathered}
w_{i}=\left(1+\frac{1}{L n} \sum_{i=1}^{m} f_{i j} L n f_{i j}\right) / \sum_{i=1}^{n}\left(-\frac{1}{L n} \sum_{i=1}^{m} f_{i j} \operatorname{Ln} f_{i j}\right) \\
w_{j}=\left\{\left[\sum_{j=1}^{m} \frac{1}{\sum_{i=1}^{m}\left(r_{i j}-r_{j}^{*}\right)^{2}}\right] \cdot \sum_{i=1}^{m}\left(r_{i j}-r_{j}^{*}\right)^{2}\right\}^{-1} \\
\lambda_{j}=\frac{w_{i} \cdot w_{j}}{\sum_{j}^{n} w_{i} \cdot w_{j}} j=1,2, \quad \cdots, n
\end{gathered}
$$

\subsection{Determine the approximate ideal solution ${ }^{[2]}$}

The TOPSIS method is used to calculate the correlation 
coefficient $\xi_{i j}$ between the evaluation index $x_{i j}$ of the relative optimal plan $M_{i}$ and the evaluation index $x_{0 j}$ of the relative optimal plan $M_{0}$ in each evaluation plan $M_{i}$, as shown in Equation (8).

$$
\xi_{i j}=\frac{\min _{i} \min _{j} n \Delta r_{i j}+\rho \max _{i} \max _{j} x \Delta r_{i j}}{\Delta r_{i j}+\rho \max _{i} \max _{j} x \Delta r_{i j}}
$$

In the formula: $\Delta r_{i j}=\left|r_{0 j}-r_{i j}\right|, \rho$ is the resolution coefficient, $0 \leq \rho \leq 1$. Usually, $\rho$ is equal to 0.5 . The correlation degree judgment matrix is weighted to obtain the correlation evaluation matrix, as shown in Equation (9).

$$
Z=\left(\lambda_{j} \xi_{i j}\right)_{m \times n}
$$

The approximation to ideal solution $V^{+}$is the attribute value, which is the best value of each candidate scheme, while the approximation to ideal solution $V^{-}$is on the contrary. Its calculation formula is shown in Equation (10). In the formula: $J^{+}$is the very large index set, $J^{-}$is the very small index set.

$$
\begin{array}{rr}
V^{+}=\left[\left(\max \lambda_{j} \xi_{i j} / j \in J^{+}\right),\right. & \left.\left(\min \lambda_{j} \xi_{i j} / j \in J^{-}\right)\right]= \\
{\left[z^{+}{ }_{1} Z^{+}{ }_{2} \cdots z^{+}{ }_{n}\right]} & (10 \mathrm{a}) \\
V^{-}=\left[\left(\max \lambda_{j} \xi_{i j} / j \in J^{+}\right),\right. & \left.\left(\min \lambda_{j} \xi_{i j} / j \in J^{-}\right)\right]= \\
{\left[z^{-}{ }_{1} z^{-}{ }_{2} \cdots z^{-}{ }_{n}\right]} & (10 \mathrm{~b})
\end{array}
$$

\subsection{The relative closeness degree and the optimal design scheme are determined}

The information entropy and TOPSIS coupling model are used to calculate the relative closeness degree of each scheme, and finally the optimal design scheme is obtained
[3]. Formula (11) is used to calculate the Euclidean space distance of each scheme, and Formula (12) is used to calculate the relative closeness degree of each scheme.

$$
\begin{aligned}
D^{+}{ }_{i} & =\sqrt{\sum_{j=1}^{n}\left(z_{i j}-z^{+}{ }_{j}\right)^{2}}, i=1,2, \cdots, m \\
D^{-}{ }_{i} & =\sqrt{\sum_{j=1}^{n}\left(z_{i j}-z^{-}{ }_{j}\right)^{2}}, i=1,2, \cdots, m \\
C_{i} & =\frac{D^{-}{ }_{i}}{D^{-}{ }_{i}+D^{+}{ }_{i}}, \quad i=1,2, \quad \cdots, m
\end{aligned}
$$

\section{Case analysis}

\subsection{Project summary}

The artificial lake of a city water system can take into account the functions of flood control and drainage, water supply and drainage, landscape storage and so on. The following is to use the information entropy and TOPSIS model established in this paper to evaluate the seepage design scheme. According to the engineering geological exploration data, within the depth exposed by the borehole, the strata in the lake area are mainly quaternary Holocene alluvial layer $\left(Q_{4}^{a l}\right)$ and Upper Pleistocene alluvial layer $\left(Q_{3}^{a l}\right)$. According to the formation genetic type, lithology and engineering geological characteristics, the exploration strata are divided into 7 layers, as shown in Table 1.

Table 1. Permeability index of each layer.

\begin{tabular}{|c|c|c|c|}
\hline Formation lithology & Bottom elevation/m & Thick/m & $\begin{array}{c}\text { Permeability } \\
\text { coefficient } \\
\left.\mathbf{k} / \times \mathbf{1 0}^{-5} \mathbf{( c m} / \mathbf{s}\right)\end{array}$ \\
\hline 1.Artificial filled soil & - & - & - \\
\hline 2.Medium silty loam & $75.47 \sim 79.03$ & $1.3 \sim 5.2$ & 9.0 \\
\hline 3.Silt & $73.91 \sim 78.03$ & $1.0 \sim 5.9$ & 500.0 \\
\hline 4.Heavy silty loam & $69.97 \sim 72.42$ & $3.2 \sim 6.1$ & 9.5 \\
\hline 5.Powder sand & $66.81 \sim 68.91$ & $1.8 \sim 3.9$ & 750.0 \\
\hline 6.Silty clay & $60.51 \sim 67.67$ & $6.3 \sim 8.4$ & 0.4 \\
\hline 7.Fine sand & not debunked & - & 900.0 \\
\hline
\end{tabular}

The seepage occurred mainly in the third layer and the fifth layer of fine sand. A large amount of lake water leakage will increase the operating cost of the lake body, and also raise the surrounding area's groundwater level, causing some areas to be submerged and salinized, and affecting the ecological environment. Therefore, antiseepage treatment must be carried out for the lake body, and the design of anti-seepage body should meet the requirements of anti-seepage during the running period of the lake body, as well as to prevent the surrounding areas from drowning salinization caused by the uplift of groundwater.

\subsection{Anti-seepage design scheme of lake body}

There are three kinds of impermeable design schemes: cement-soil mixing pile $\left(M_{1}\right)$, plastic concrete impermeable wall $\left(M_{2}\right)$ and loam overlay $\left(M_{3}\right)$. Cementsoil mixing pile and plastic concrete impervious wall have good impervious effect. The combination of impervious during construction and permanent impervious wall can reduce the cost of drainage and facilitate the operation and management in later period. However, they have higher 
requirements for construction technology. In addition, the cost of plastic concrete impervious wall is high, which also has some influence on the environment. Loam overlay construction technology is simple, local materials can be used, has little impact on the environment, but the antiseepage effect is not ideal, the protective body overdigging project is large, the investment cost is high, the later maintenance is also difficult. The leakage volumes of the three impermeable schemes of cement-soil mixing pile $\left(M_{1}\right)$, plastic concrete impermeable wall $\left(M_{2}\right)$ and loam overlay $\left(M_{3}\right)$ were 2.09 million $\mathrm{m}^{3} / \mathrm{a}$, 1.56 million $\mathrm{m}^{3} / \mathrm{a}$ and 4.2 million $\mathrm{m}^{3} / \mathrm{a}$, respectively. The main engineering quantities are as follows: the total length is $4,350 \mathrm{~m}$, the wall is $29,295 \mathrm{~m}$, over excavated earthwork is 1.375 million $\mathrm{m}^{3}$ and the bedding is 1.375 million $\mathrm{m}^{3}$. The total investment is 5.74 million, 12.01 million and 18.5 million respectively.

\subsection{Comprehensive analysis of seepage prevention design scheme}

Based on the information entropy and TOPSIS coupling model, the design scheme of artificial lake seepage control was analyzed comprehensively and optimized. The seven selected experts scored the evaluation indexes in the alternative impermeable design scheme according to the percentage system ${ }^{[4]}$, thus making a quantitative analysis of the design scheme. The standardized evaluation matrix is shown in Formula (13). MATLAB R2013B was used to program the coupling model of information entropy and TOPSIS, and the evaluation matrix was solved according to the steps of the coupling model, and the weight and relative closeness degree of the impermeable scheme were obtained ${ }^{[5]}$.

$X_{1}=$

$\left[\begin{array}{llllll}1.245 & 1.431 & 1.473 & 1.452 & 0.801 & 1.207 \\ 0.436 & 1.237 & 1.235 & 0.456 & 0.416 & 0.528 \\ 1.149 & 1.218 & 1.216 & 0.951 & 0.739 & 1.216 \\ 1.232 & 0.527 & 0.803 & 1.135 & 1.416 & 1.239 \\ 0.761 & 0.807 & 0.677 & 1.610 & 0.809 & 1.139 \\ 1.261 & 0.616 & 1.217 & 0.861 & 1.126 & 0.825 \\ 1.171 & 1.163 & 0.367 & 0.873 & 1.2841 & 0.901\end{array}\right]$

The weight of the index $w_{1}=$ (0.182 0.1690 .2280 .1320 .076$)$ was calculated by information entropy. The quantitative indexes of the three impermeable design schemes $M_{1}, M_{2}$ and $M_{3}$ corresponding to each scheme are shown in Table 2.

Table 2. Quantitative index of three schemes.

\begin{tabular}{|c|c|c|c|}
\hline $\begin{array}{c}\text { Package } \\
\text { number }\end{array}$ & $\begin{array}{c}\text { Work } \\
\text { efficiency }\end{array}$ & $\begin{array}{c}\text { Time limit } \\
\text { for a } \\
\text { project } \\
\text { (month) }\end{array}$ & $\begin{array}{c}\text { Construction } \\
\text { technology }\end{array}$ \\
\hline$M_{1}$ & 0.91 & 15 & 0.89 \\
\hline$M_{2}$ & 0.94 & 17 & 0.87 \\
\hline$M_{3}$ & 0.88 & 13 & 0.92 \\
\hline Investment & $\begin{array}{c}\text { Construction } \\
\text { difficulty }\end{array}$ & \multicolumn{2}{|c|}{ Environmental impact } \\
\hline 574 & 0.82 & \multicolumn{2}{|c}{0.70} \\
\hline
\end{tabular}

\begin{tabular}{|l|l|l|}
\hline 1201 & 0.85 & 0.75 \\
\hline 1850 & 0.71 & 0.65 \\
\hline
\end{tabular}

According to Table 2, the optimal design factors can be obtained $M_{0}=(0.94130 .875740 .710 .65)$ Accordingly, the attribute matrix of scheme set $M$ to the index is listed. The weight $w_{i}=$ (0.362 0.2110.2170.0980.061) of each index was obtained by TOPSIS method, and the comprehensive

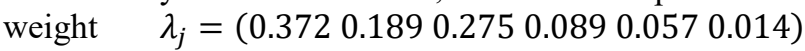
was obtained by coupling model. The correlation evaluation matrix of the multi-objective decision made up of 3 groups of design schemes and corresponding indicators is shown in Formula $Z$.

$Z=\left[\begin{array}{llllll}0.269 & 0.161 & 0.286 & 0.071 & 0.063 & 0.018 \\ 0.351 & 0.188 & 0.174 & 0.044 & 0.037 & 0.007 \\ 0.313 & 0.118 & 0.231 & 0.031 & 0.032 & 0.005\end{array}\right]$

The correlation evaluation matrix was solved, and the corresponding values were obtained:

Ideal solution

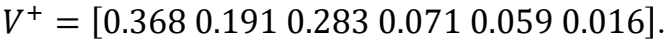

Negative ideal solution

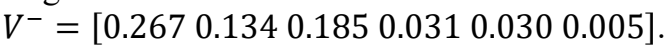

Using the information entropy and TOPSIS coupling model, the Euclidean space distance of each scheme is calculated as follows:

$$
\begin{aligned}
& D^{+}=\left[\begin{array}{lll}
0.0973 & 0.1062 & 0.1052
\end{array}\right], \\
& D^{-}=\left[\begin{array}{lll}
0.1231 & 0.1189 & 0.0703
\end{array}\right] .
\end{aligned}
$$

The relative closeness degree of each scheme $C_{i}=$ [ 0.5610 .5020 .382$]$. According to the analysis results of the coupling model, the relative closeness degree of $M_{1}$ is 0.561 , with the best rationality. The results of the coupling model are in good agreement with the practice. In the process of actual evaluation, it is often difficult to find effective historical sample data, so the key of model evaluation is to mine the data, objectively assign the value and analyze the closeness degree of evaluation scheme. At the same time, the evaluation result of the model is little affected by parameters.

\section{Conclusion}

Based on the coupling model of information entropy and TOPSIS, the evaluation indexes of the design scheme are analyzed quantitatively. At the same time, it is more objective and reasonable to mine and analyze data and assign weights through TOPSIS method and assign comprehensive weights to evaluation indexes. Based on the information entropy and TOPSIS coupling model, based on the objective weight and the calculation of closeness degree, there is no need to conduct sample training to the neural network, which has a wide range of application, a clear idea of model construction, and is easy to implement.

\section{References}

1. Ding Kun, Jin Juliang, Zhang Libing, etc. Projection pursuit model for evaluation of wastewater treatment 
plant planning and reconstruction decision based on information entropy $[\mathrm{J}]$. Water and wastewater treatment and drainage, 36, 5 (2010)

2. Chen Hongyan. Improved Ideal solution method and its application in engineering Bid evaluation [J]. Application of systems engineering theory and method, (2004)

3. Zhou Huijun, Xiao Yingjie, Zhang Hao. Optimization of wharf design scheme based on improved grey correlation analysis $[\mathrm{J}]$. Journal of Shanghai maritime university, 32, 3 (2011)

4. Huo Yingbao, Han Zhijun. Research on multi-index weight determination method based on generalized maximum entropy principle and genetic algorithm [J]. Mathematical statistics and management, 24, 3 (2005)

5. Jin Juliang, Wu Yonglin, Wang Mingwu. Journal of Sichuan university: Engineering science edition, 36, 4 (2004) 